Research paper

\title{
Prediction of rock block stability and scour depth in plunge pools
}

POOYAN ASADOLLAHI, Department of Urban Architecture and Community Planning, The University of the District of Columbia, 4200 Connecticut Avenue NW, Washington, DC 20008, USA.

Email:pooyanas@gmail.com (authorforcorrespondence)

FULVIO TONON, Department of Civil Engineering, The University of Texas at Austin, I University Station C1792, Austin, $T X 78712, U S A$.

Email: tonon@mail.utexas.edu

MATTEO P.E.A. FEDERSPIEL, Laboratory of Hydraulic Constructions (LCH), Ecole Polytechnique Fédérale de Lausanne (EPFL), Station 18, CH-1015 Lausanne, Switzerland.

Email: matteo.federspiel@epfl.ch

ANTON J. SCHLEISS (IAHR Member), Laboratory of Hydraulic Constructions (LCH), Ecole Polytechnique

Fédérale de Lausanne (EPFL), Station 18, CH-1015 Lausanne, Switzerland.

Email: anton.schleiss@epf.ch

\begin{abstract}
Block Stability in 3 Dimensions (BS3D) is an incremental-iterative algorithm and code to analyse general failure modes of rock blocks subjected to generic forces, including non-conservative forces such as water pressure. This algorithm is used to investigate the effect of high-velocity water jet impact on the stability of single rock blocks in plunge pools. After reviewing the literature, an approach is proposed to estimate the dynamic water pressure fluctuations at the pool bottom and in rock fractures. The approach is validated using an experimental study. In addition, by comparing the results of these analyses to additional experimental results, a scour threshold is introduced for plunge pools. It is found that if the maximum upward block displacement is larger than a quarter of the block height, the block is most probabiy removed from its mould. The proposed approach and threshold are validated using case histories that indicate excellent match between prediction and observed scour depth.
\end{abstract}

Keywords: Dam safety, fracture, rock, scour, spillway

\section{Introduction}

Standard dam risk assessment includes consideration of scour for the spillway and the energy dissipator. For concrete and masonry dams, it also includes the assessment of dam overtopping and the scour potential at the foundations. High-velocity plunging jets can result in scouring of the rock riverbed or the dam toe foundation. Assessment of the extent of scour is necessary to ensure the dam safety and to guarantee the stability of its abutments. Currently, there is no formulation for evaluating scour caused by general failure modes of rock blocks of general shape and subject to arbitrary loading (e.g. gravity, reinforcement, dam loads) and to the plunge pool water pressures. Available approaches to scour evaluation have limitations, which are explained below.
Bollaert's dynamic impulsion (DI) method (Bollaert 2002, Bollaert and Schleiss 2005) is limited to vertical translational failure (static failure mode) of parallelepiped rock blocks with one face at the plunge pool bottom. Indeed, roto-translational failures are common even for parallelepiped blocks subjected to pressure fluctuations (Fiorotto and Rinaldo 1992).

Annandale's $(1995,2006)$ erodibility index method is a classification method, as opposed to analytical or numerical methods based on mechanical principles, applicable to entire rock masses, but is not applicable to single rock blocks, which typically are critical for dam stability (Goodman and Powell 2003).

As for numerical methods of discontinuous rock masses, 3D distinct element code (3DEC) by Itasca (1999) has serious limitations in the dynamics of rigid bodies because it assumes that

Revision received 24 August 2011/Open for discussion until 30 June 2012. 
the inertia tensor is always diagonal (Hart et al. 1988, Itasca 1999), i.e. rotations are assumed to be parallel to the applied resultant moment. In reality, rotations are parallel to the applied moment if and only if the applied resultant moment is parallel to a principal axis of inertia. $3 \mathrm{D}$ discontinuous deformation analys is (3D DDA) by Jang and Lee (2002) as well as 3DEC use contact points at the vertices of the contact areas to calculate constraint forces: this does not allow for path-dependent behaviour of discontinuities. 3D-DDA assumes that all forces are conservative, and thus cannot handle follower forces, such as water pressure.

Herein, the stability of single rock blocks in plunge pools is investigated using Block Stability in 3D (BS3D), a Fortran code implemented by Asadollahi (2009) based on the algorithm introduced by Tonon (2007). BS3D follows the equilibrium path of a single rock block by using an incremental-iterative algorithm. It analyses general failure modes of rock blocks subject to generic forces, including non-conservative forces such as water forces. These are not conservative because water pressure is orthogona! to the surface onto which it is applied, and therefore water forces depend on the orientation of the surface itself (in conservative forces, the work done in moving a particle between two points is independent of the taken path). The algorithm uses consistent stiffness matrices that fully exploit the quadratic convergence of the adopted Newton Raphson iterative scheme. The algorithm accounts for large block displacements and rotations, which, together with non-conservative forces render the stithess matrix non-symmetric. The algorithm accounts for in situ stress, progressive failure, and fracture dilatancy, which introduce non-symmetric rank-one modifications to the stiffness matrix. Failure modes may originate from a limit point or from dynamic instability (divergence or flutter). Equilibrium paths emanating from bifurcation points are followed by the algorithm, which identifies both static and dynamic failure modes; if a failure mode is detected, BS3D gives the initial acceleration of the rock block. BS3D has proven capable of detecting numerically challenging failure modes, such as rotations about only one point, and was validated using physical models and case histories (Tonon and Asadollahi 2008).

This work is organized as follows. Section 2 describes an approach to estimating pressure forces generated in plunge pools due to high-velocity jet impacts. Section 3 proposes a failure criterion for jointed rock masses. In Section 4 , the scour model implemented in BS3D is calibrated and validated using the results of several experimental studies as well as case histories and prototypes, followed by conclusions in Section 5. A deterministic approach is used throughout.

\section{Pressure forces generated in plunge pools}

Studies on pressure fluctuations in plunge pools include those of Cola (1965), Hartung and Häusler (1973), Beltaos and Rajaratnam (1973), Mason and Arumugam (1985), Franzetti and Tanda (1987), Lopardo (1988), Armengou (1991), May and Willoughby (1991), Puertas and Dolz (1994), Ervine et al. (1997), Bollaert (2002), Bollaert and Schleiss (2003a, 2003b), or Ursino et al. (2003). The maximum pressure in a fracture is assumed to occur at the same time as the minimum pressure on the pool floor, and pressures are evaluated as stated in Table 1. The net upward pressure coefficients so calculated for different magnitudes of

Table 1 Equations used to calculate pressures at floor bottom and in rock features

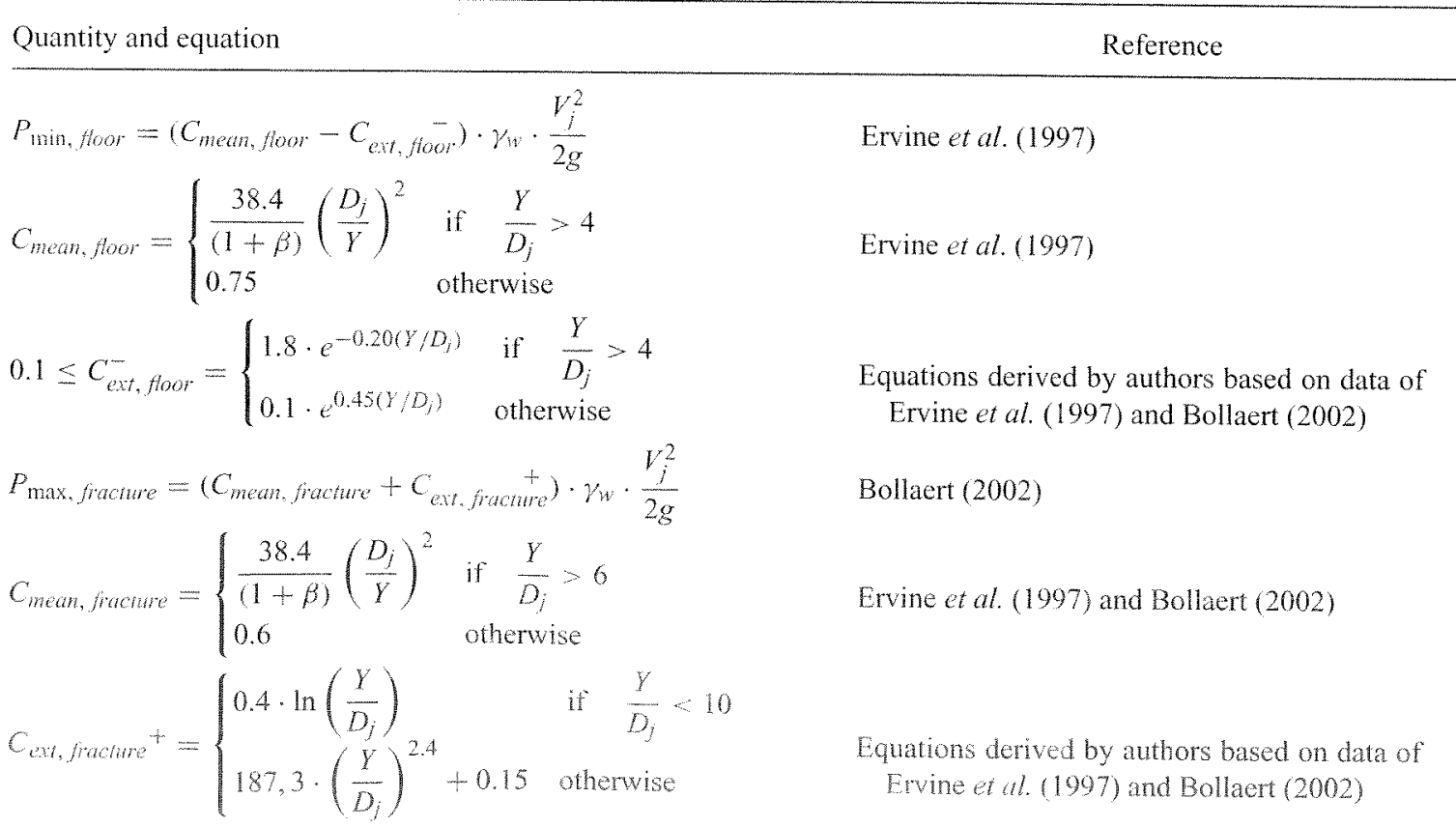

Note: $V_{j}=$ jet velocity at pool surface, $\gamma_{w}=$ unit weight of water, $D_{j}=$ jet diameter at pool surface, $Y=$ pool depth, $\beta=$ free air content. 
$Y / D_{j}$ were found to correspond well with those experimentally measured by Bollaert (2002) and to be in-line with the values obtained by Liu et al. (1998) by measuring the net uplift forces on scaled versions of rock blocks in plunge pools. Maximum pressure fluctuations, as opposed to root-mean-square values, are also typically used in the stability analysis of stilling basin slabs (Fiorotto and Rinaldo 1992, Bellin and Fiorotto 1995, Fiorotto and Salandin 2000).

The assumption that pressure fluctuations in each fracture are independent of each other is also based on considerations of the correlation function for pressure fluctuations because the integral scale of the correlation function for pressure fluctuations is small when compared with the typical dimension of a rock block (Melo et al. 2006); if the horizontal characteristic block dimension is at least twice the integral scale, then the pressure fluctuations at two fractures are independent (Fiorotto and Rinaldo 1992). This was confirmed in the facility developed by Bollaert (2002), which generated frequency spectra in good agreement with spectra of real high-velocity air-water jets. This assumption is a worstcase scenario because it entails that the minimum pressure at one fracture can occur simultaneously with the maximum pressure at another fracture, and vice versa. As a consequence, if a block has $n$ faces, the stability analysis will be run $2^{n}$ times to cover all possible combinations of pressure distributions on the block faces. Since the maximum and minimum dynamic pressure coefficients were obtained from $2 \mathrm{~min}$ records, their values must be doubled for a $24 \mathrm{~h}$ run time, which is considered representative of continuous operation of a plunge pool or a stilling basin (Ervine et al. 1997, Fiorotto and Salandin 2000).

\section{Proposed failure criterion for jointed rock}

\subsection{Impulsive nature of applied forces}

The typical duration of maximum pressure fluctuations is of the order of $5 \mathrm{~ms}$ (Bollaert 2002), and there is $75 \%$ probability that pressure fluctuations persist less than $6 \mathrm{~ms}$ at the pool bottom (Manso 2006). For core jet conditions $\left(Y / D_{j}<4\right)$, this value drops to $4 \mathrm{~ms}$, whereas for transition and developed jet conditions ( $4<Y / D_{j}<6$ and $Y / D_{j}>6$, respectively), this value is higher than $4 \mathrm{~ms}$. Herein, the block is assumed to be subjected to its constant unbalanced force at failure for the maximum duration of an extreme pressure fluctuation, i.e. $5 \mathrm{~ms}$. This assumption was successfully used for stilling basins (Fiorotto and Salandin 2000 ). In the absence of measurements or any other information regarding the maximum duration of an extreme pressure fluctuation, it is recommended to adopt a minimum of $5 \mathrm{~ms}$ and half of the fissure natural period as appropriate values.

BS3D follows the block in its static condition until equilibrium is possible between the active and reaction forces. As the block fails, the active force that cannot be in equilibrium with the constraints (nearby blocks) imparts an acceleration to the block (Tonon 2007). By applying rigorous rigid body dynamics, the formulation then computes the initial acceleration of the block and its subsequent displacement by taking into account the inertia of the rock block. This displacement under maximum pressure fluctuations was experimentally observed by Yuditskii $(1967,1971)$, who presented the first conceptual model of the rock scouring process based on pressure fluctuations on rock blocks. His procedure is similar to that proposed here, in that it is based on an evaluation of the maximum instantaneous pressure separating a rock block from the matrix. For increasing pool depths, he compared the maximum pressure gradient amplitude originated by jet impact with a limit pressure value corresponding to the equilibrium condition. He also conducted more than 2000 tests focusing on the mechanisms of block ejection for varying scour depths, relative block size, block density, and joint thickness. One interesting observation of Yuditskii $(1967,1971)$ later made by Melo et al. (2006) is: "the block is ejected, neither by one pressure fluctuation of high amplitude nor by a succession of pressure fluctuations of high amplitude, but by one large average pressure that is established in the joint underneath the block following a small vertical displacement. The opening of the joint that allows this small vertical displacement is done by one pressure fluctuation of high amplitude". What is interesting is that the flow and rock mass conditions that led to a small block displacement then led to block ejection from the rock mass. In other words, there is experimental evidence that a block is ejected if and only if it first fails according to one of the failure modes captured by the proposed stability analysis.

\subsection{Scour threshold}

Below, a scour threshold is introduced for the cases in which the stability analysis predicts that a block of mass $m$ fails in a translational mode, i.e. the dynamic failure mode obtained using BS3D gives an acceleration in one direction of magnitude $a$, without rotation. At failure, the block is assumed to be subjected by this constant acceleration for the maximum duration $\Delta t$ of an extreme pressure fluctuation, i.e. $5 \mathrm{~ms}$, causing a velocity $V_{\Delta t}=m a$.

After $\Delta t$, it is assumed that the block moves with the initial velocity $V_{\Delta t}$ for a duration equal to $t_{u p}=T_{c} / 2-\Delta t$, where $T_{C}=2 \mathrm{~L} / \mathrm{C}$ is the natural period of the characteristic length of the fractures that isolate the block (Annandale 2006), $c$ is the pressure wave celerity, which may be estimated for air-water flow using the equation of Annandale (2006), and $L$ is the characteristic fracture length $\left(x_{b}+2 z_{b}\right)$, where $x_{b}$ and $z_{b}$ are length and height of the block, respectively. The maximum upward displacement of the block $h_{t p}$ is thus

$$
h_{u p}=\frac{V_{\Delta t} \cdot\left(T_{c}-\Delta t\right)-g \cdot t_{u p}^{2}}{2}
$$

Bollaert (2002) proposed that a rock block is considered to be definitely removed from its matrix if $h_{u p} / z_{b}>1$. However, Bollaert and Schlciss (2005) found that the ultimate scour depth observed at Cabora Bassa dam corresponds to $h_{t p} / z_{t}=0.20$, which is inconsistent with the above criterion. Herein, BS3D was used to simulate the test data of Martins (1973). Based on 
these, it is suggested that a block is most likely to be removed if $h_{i i p} / z_{b}>0.25$ (Section 4.2).

\section{Application, calibration, and validation of scour model}

The experimental study of Federspiel et al. (2009) is used to validate the dynamic water pressures in Section 2, and BS3D to determine the stability of a rock block together with its displacements. Secondly, the failure criterion of Section 3 is calibrated by employing Martins' (1973) data. The entire scour model and BS3D algorithm are then validated using three case histories and prototypes.

\subsection{Experimental study}

Federspiel et al. (2009) conducted a scaled experimental study to investigate the behaviour of a single rock block modelled as a hollow steel cube instrumented with a large series of pressure transducers, accelerometers, and displacement transducers. The sizes of the jet and the block were such that the whole block surface was subjected to characteristic pressure fluctuations and the block size was in the range of the prevailing turbulence structures. On prototypes, the jet dimensions are larger so that similar conditions apply to larger rock blocks when compared with the laboratory-instrumented block.

The scaled plunge pool consisted of a $3 \mathrm{~m}$ diameter, $1.4 \mathrm{~m}$ high cylindrical basin. The water was supplied with a $72 \mathrm{~mm}$ diameter cylindrical jet outlet. The maximum discharge was $1201 / \mathrm{s}$, corresponding to maximum jet outlet velocities of $30 \mathrm{~m} / \mathrm{s}$. The measurement box of length $=$ width $=402 \mathrm{~mm}$ and height $=$ $340 \mathrm{~mm}$ was composed of $20 \mathrm{~mm}$ thick steel plates. Inside the box, a large series of cavities housed pressure and displacement manducers. In its centre, a cavity of length $=$ width $=202 \mathrm{~mm}$ me height $=201 \mathrm{~mm}$ housed the cubic highly-instrumented the $1200 \mathrm{~mm}$ side length. The width of the steel plates was mplinel to obtain a block unit weight similar to real rock, i.e. $23 \mathrm{k} / \mathrm{m}^{3}$. On top of the block, holes were pre-perforated to fix the pressure transducers. Between the measurement box and the highly-instrumented block, a 3D fissure of $1 \mathrm{~mm}$ width was created. Both units were placed inside the basin that simulated the plunge pool.

The instrumentation consisted of a data acquisition system, 12 pressure transducers, two displacement transducers with a precision better than $0.01 \mathrm{~mm}$, and an accelerometer transducer with a frequency range between 1 and $10 \mathrm{kHz}$. The pressure transducers fixed within the vertical plane allowed the pressure field around a block to be reconstructed. The displacement transducers and the accelerometer had fixed positions under the block in the "measurement box" and in the block, respectively.

Tests were performed with a fiat bottom and a water jet centred in the middle of the highly-instrumented block. Two plunge pool water levels of $Y=0.1 \mathrm{~m}$ and $0.6 \mathrm{~m}$, and four jet outlet velocitis of $19.6,22.1,24.6$, and $27.0 \mathrm{~m} / \mathrm{s}$ were tested. The $Y=0.1 \mathrm{~m}$ water level in the plunge generated a core jet of only $Y / D_{j}=1.39$, while for $Y=0.6 \mathrm{~m}$ resulted in a ratio of $Y / D_{j}=8.33$. For each water level and jet velocity, three runs were performed. The data acquisition frequency was $1 \mathrm{kHz}$ and the recording time $60 \mathrm{~s}(60,000$ samples for each transducer $)$.

The mean pressure coefficients $C_{p}$ recorded directly under the jet axis for core jet impact were in good agreement with the theoretical curves of Ervine et al. (1997) and with previous pressure records of Bollaert (2002) and Manso (2006). The $C_{p}$, values recorded away from the jet axis and inside the joints around the block were generally less than the mean pressures under the jet axis, as also observed by Bollaert (2002) and Manso (2006). For developed jet impact, however, the recorded values were higher than the theoretical curves and correspond to values for core jet impact. This is due to the jet deflecting the plunge pool water level and locally lowering it. Further, the measured pressure fluctuation coefficients $C_{p}^{\prime}$ were in good agreement with theory for core jets but differed slightly from developed jet theory. As such, the fluctuating component is lower than the theoretical curves, which again would correspond to a core jet rather than a developed jet.

Federspiel et al. (2009) recorded the maximum vertical block displacement $h_{u p, e x p}$ and the maximum net uplift hydrodynamic pressure $P_{\text {net, exp }}$ as the difference between the maximum dynamic water pressure on the bottom fracture and the minimum dynamic floor water pressure. The duration of the maximum pressure fluctuation was $1 \mathrm{~ms}$. The accuracy of the equipment was $\pm 1 \mathrm{~ms}$. The recorded displacements refer to a special case since the jet impact was perfectly aligned with the block centre. Therefore, the velocity change had a small effect and the pressure at the stagnation point kept the displacements to almost a constant value.

For each tested water level and jet velocity, BS3D analyses were performed to predict the maximum vertical block displacement $h_{u p}$ by using both the measured maximum net uplift hydrodynamic pressure from Federspiel's experiments and the hydrodynamic pressures determined as explained in Section 2. Because of the short test duration, the dynamic pressure magnitudes were estimated without considering a coefficient 2 accounting for long duration events in numerical simulations. In Federspiel's test apparatus, the jet velocity was adjusted by water discharge and the jet breakup length was very short, i.e. $\sim 1 \mathrm{~m}$. Therefore, $\beta=1-2 \%$ was used for the air content (Ervine et al. 1997). Consequently, $c \cong 100 \mathrm{~m} / \mathrm{s}$ (Annandale 2006) and $T_{c}=0.012 \mathrm{~s}$ for $L=0.6 \mathrm{~m}$.

In BS3D simulations, Young's modulus and Poisson's ratio of the steel plates forming the block and the mould were equal to $200 \mathrm{GPa}$ and 0.3 , respectively. Figure 1 compares the measured and BS3D-predicted maximum vertical block displacements. For both core and developed jets, BS3D predicts the maximum block displacement well if the hydrodynamic input pressures are equal to the net uplift dynamic water pressures measured by Federspiel et al. (2009). These results validate the BS3D algorithm excluding the estimation of the hydrodynamic pressure. The results of the analyses with dynamic water pressure estimated using the approach of Section 2 show that for core jets $\left(Y / D_{i}<6\right)$ and developed jets $(Y / D,>6)$ the maximum vertical block 

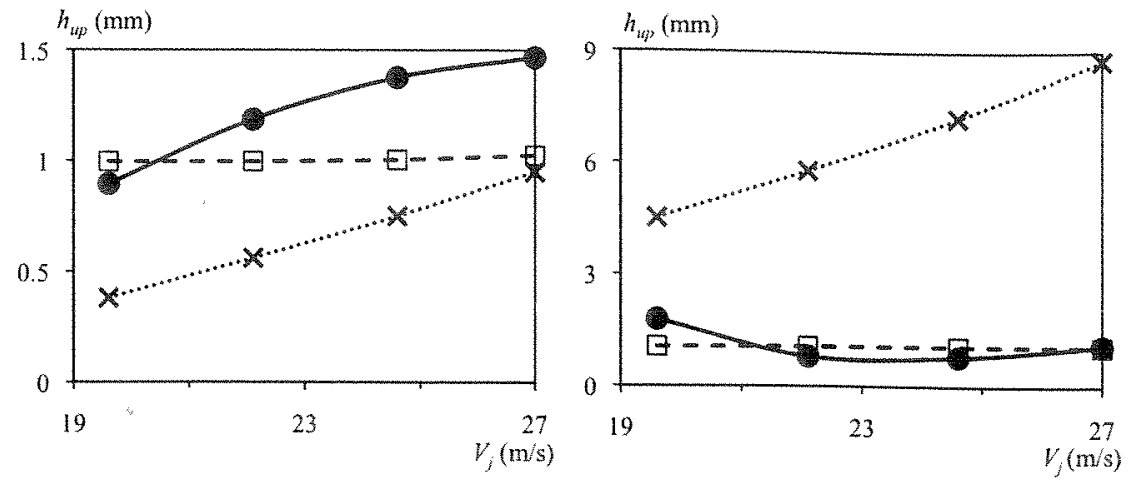

Figure 1 Comparison of maximum vertical block displacements ( $\square$ ) measured (Federspiel et al. 2009), predicted by BS3D using ( $\bullet$ ) measuri dynamic pressures, and $(\times)$ dynamic pressures as in Section 2 for (a) $Y=0.1 \mathrm{~m}$ (core jet $Y / D_{j}=1.39$ ), (b) $Y=0.6 \mathrm{~m}\left(\right.$ developed jet $Y / D_{j}=8.3$

displacement is underestimated and overestimated, respectively. These errors are caused by the discrepancy between the actual dynamic water pressures experienced by the block and the water pressures estimated using the approach of Section 2. However, this approach seems to be the best method currently found in the literature.

In Fig. 1, the dashed curve refers to predictions based on dynamic water pressures in Section 2. The dot-dashed curve refers to predictions based on measured water pressure. Loss of accuracy in BS3D, if any, should be quantified by comparing the dot-dashed curve with the measured displacements (continuous curve). In Fig. 1(b), the dot-dashed curve nearly collapses with the experimentally measured displacements, indicating that BS3D results are numerically accurate and, for a developed jet, the assumptions of Section 3 lead to excellent results. Since $\mathrm{BS} 3 \mathrm{D}$ is free from numerical inaccuracies, the discrepancies in Fig. 1(a) are attributed to decreased validity of the assumptions in Section 3. In particular, the predictions are excellent for jet velocities of $20-22 \mathrm{~m} / \mathrm{s}$, and the relative error increases then to $50 \%$ as the velocity increases. In a core jet, this is attributable to fluctuations of the water velocity on top of the block during the time period $\Delta t$, whereas the model assumes constant pressure equal to the worst combination that causes uplift.

\subsection{Action of free jets on rocky river-beds}

Martins (1973) describes a riverbed test facility made up of equal cubic blocks containing mortar of $22 \mathrm{kN} / \mathrm{m}^{3}$ unit weight, systematically arranged without cohesion. A total of 90 tests was conducted, resulting from three impact angles $\left(40^{\circ}, 55^{\circ}\right.$, and $\left.70^{\circ}\right)$, three jet diameters at the pool surface $(5,6$, and $7 \mathrm{~cm})$, two block widths ( $b=3$ and $4.7 \mathrm{~cm}$ ), and five depths of the water cushion. The free air content $\beta$ ranged from $2 \%$ to $70 \%$ resulting in $c \cong 25 \mathrm{~m} / \mathrm{s}$ for $\beta \geq 30 \%$ (Annandale 2006). Consequently, $\beta=30 \%$ and $c \cong 25 \mathrm{~m} / \mathrm{s}$ were adopted in BS3D simulations. For $b=3 \mathrm{~cm}(L=9 \mathrm{~cm}), T_{c}=8 \mathrm{~ms}$, and for $b=4.7 \mathrm{~cm}(L=$ $14.1 \mathrm{~cm}), T_{c}=14 \mathrm{~ms}$. The dynamic pressures were estimated as described in Section 2 without considering the coefficient 2 accounting for long duration events in the numerical simulations.

The ratio of $h_{t p} / z_{b}$ was calculated for all 90 tests. For $b=3 \mathrm{~cm}$, the $h_{i p} / z_{h}$, ratio varied within $[0.14,0.55]$ with an average of 0.29 , whereas for $h=4.7 \mathrm{~cm}$ the $h_{u p} / z_{b}$ ratio was within $[0.13,0.55]$ with an average of 0.25 . Consequently, block is most likely removed from its mould if $h_{u p} / z_{b}>0.25$.

Scour depths were also predicted for all 90 tests using BS3 together with the method described in Section 2 to estima hydrodynamic pressures caused by jet impact and the calibrat scour threshold $\left(h_{u p} / z_{b}>0.25\right)$. The ratio of predicted to me sured scour depths was in the range of $[0.44,1.70]$ for $b=3.0 \mathrm{cr}$ with an average and standard deviation of 1.07 and 0.31 , respe tively. For $b=4.7 \mathrm{~cm}$, the range was $[0.39,1.52]$ with an avera and standard deviation of 0.88 and 0.30 , respectively. The results validate the ability of the suggested approach in predictir scour depth.

\subsection{Case study of Cabora Bassa dam}

The Cabora Bassa dam is located on Zambezi River in Mozar bique. Its tailwater level is at $225 \mathrm{~m}$ a.s.1. with a depth of near $50 \mathrm{~m}$ above the riverbed, whose elevation is at $\sim 170 \mathrm{~m}$ a.s The rock is mainly fractured gneiss and gabbro and lamprophy dykes (Bollaert 2002, Bollaert and Schleiss 2005).

Hydraulic model tests at a 1/75 scale were conducted Laboratório Nacional de Engenharia Civil (LNEC), Lisb (Ramos 1982). A movable bed model was used, made of weak cemented gravel. An extensive survey of the scour hole show that its deepest point was located at $158 \mathrm{~m}$ a.s.1., i.e. $22 \mathrm{~m}$ belo the original riverbed. The outlet jet diameter was estimated the equivalent hydraulic diameter of the $6 \mathrm{~m} \times 7.8 \mathrm{~m}$ rectangul outlet, i.e. $7.7 \mathrm{~m}$. The air concentration was high with $\beta=60^{\circ}$. resulting in $c \cong 100 \mathrm{~m} / \mathrm{s}$. The characteristic block length of 2 (based on model tests performed at LNEC) yields $T_{c}=0.18 \mathrm{sf}$ $L=6 \mathrm{~m}$. The unit block weight was $20 \mathrm{kN} / \mathrm{m}^{3}$ (Bollaert $200 \%$ Based on these values, two test series were performed using $t$ DI method to estimate the ultimate scour depth using BS3D ar either the Bollaert (2002) or the Bollaert and Schleiss's (200 approach. The following results are compared with the me sured value of $158 \mathrm{~m}$ a.s.l. and validate BS3D in predicting sco depth:

- Bollaert (2002) assumed $V_{j}=35 \mathrm{~m} / \mathrm{s}, D_{j}=8 \mathrm{~m}$; the method gives an ulimate scour depth of $133 \mathrm{~m}$ a.s. 1. where: BS3D gives $161 \mathrm{~m}$ a.s.l. 
- Bollaert and Schleiss (2005) assumed $V_{j}=42 \mathrm{~m} / \mathrm{s}, D_{j}=$ $7.2 \mathrm{~m}$; the DI method gives an ultimate scour depth of $152 \mathrm{~m}$ a.s.l., whereas BS3D's gives $155 \mathrm{~m}$ a.s.1.

\subsection{Two cases of scour in prototypes}

Two published cases of scour in prototypes were analysed using BS3D and the method explained in Section 2 to estimate the hydrodynamic pressure. In each case, the maximum vertical displacements of the rock blocks at the given scour depth was calculated:

(1) Picote prototype dam in Portugal (Cunha and Lencastre 1966): the side length of the cubic blocks was $1.05 \mathrm{~m}$, the water cushion $36 \mathrm{~m}$, the fall height $45 \mathrm{~m}$ with a discharge of $7000 \mathrm{~m}^{3} / \mathrm{s}, V_{j}=29.71 \mathrm{~m} / \mathrm{s}$ and $D_{j}=17.32 \mathrm{~m}$. The measured scour depth was $19 \mathrm{~m}$. Estimating $\beta=10 \%$, BS3D gave a maximum vertical block displacement of $0.311 \mathrm{~m}$ $\left(h_{u p} / z_{b}=0.30\right)$.

(2) Kondopoga prototype dam, USSR (Kamenev 1965): the side length of the cubic blocks was $0.14 \mathrm{~m}$, the water cushion $1.45 \mathrm{~m}$, the fall height $11.4 \mathrm{~m}$, with a discharge of $70 \mathrm{~m}^{3} / \mathrm{s}$, $V_{j}=14.95 \mathrm{~m} / \mathrm{s}$ and $D_{j}=2.44 \mathrm{~m}$. The measured scour depth was $4.8 \mathrm{~m}$. Estimating $\beta=2.5 \%, \mathrm{BS} 3 \mathrm{D}$ gave a maximum vertical block displacement of $0.039 \mathrm{~m}\left(h_{u p} / z_{b}=0.28\right)$.

Note that, at the reported ultimate scour depth, the ratios of $h_{u p} / z$ determined using BS3D agree with the failure criterion of Section 4.2 and the block is likely to be removed if $h_{u p} / z_{b}=0.25$.

\section{Conclusions}

\footnotetext{
The wability of single rock blocks in plunge pools was invesrented. The introduced approach to estimate pressure forces generated in plunge pools due to high-velocity jet impact consists of assuming that the maximum/minimum pressures in a fracture occur at the same time as the minimum/maximum pressures on the pool floor. The block displacement was calculated by subjecting the block to its constant unbalanced force at failure applied for the maximum duration of an extreme pressure fluctuation, which was estimated using empirical equations. Experimental studies were used to validate this approach together with the ability of the BS3D method in determining the stability of rock blocks and their displacement. Based on these simulations, it was proposed to consider that a rock block is most likely to be removed if the ratio between maximum upward block displacement and the block height is larger than $1 / 4$. The present approach was validated using three prototype case studies. The calculated scour depths match these observed, and can be obtained by using parameters determined from standard knowledge. In the cases examined (arrangements of cubic blocks), the present analyses indicate that scour and scour depth may be predicted if the failure mode is assumed to be a static translation.
}

\section{Notation}

$a$ = block acceleration caused by unbalance force $\left(\mathrm{m} / \mathrm{s}^{2}\right)$

$c=$ pressure wave celerity $(\mathrm{m} / \mathrm{s})$

$C=$ dynamic pressure fluctuation coefficient (dimensionless)

$D_{j}=$ jet diameter at pool surface $(\mathrm{m})$

$F=$ unbalanced force due to maximum dynamic pressure fluctuation $(\mathrm{N})$

$F_{\Delta t}=$ net impulse on block (N)

$g=$ gravity acceleration $\left(\mathrm{m} / \mathrm{s}^{2}\right)$

$h_{u p}=$ maximum upward block displacement $(\mathrm{mm})$

$L=$ characteristic fracture length $(\mathrm{m})$

$m=$ block mass $(\mathrm{kg})$

$P=$ dynamic pressure $\left(\mathrm{N} / \mathrm{m}^{2}\right)$

$T_{c}=$ natural period of open-ended joint (s)

$V_{j}=$ jet velocity at pool surface $(\mathrm{m} / \mathrm{s})$

$V_{\Delta t}=$ initial block velocity $(\mathrm{m} / \mathrm{s})$

$x_{b}=$ block length $(\mathrm{m})$

$Y=$ pool depth $(\mathrm{m})$

$z_{b}=$ block height $(\mathrm{m})$

\section{Greek symbols}

$\beta=$ free air content $(\%)$

$\gamma_{w}=$ unit weight of water $\left(\mathrm{N} / \mathrm{m}^{3}\right)$

$\Delta t=$ maximum duration (s)

$\rho=\operatorname{density}\left(\mathrm{kg} / \mathrm{m}^{3}\right)$

\section{References}

Annandale, G.W. (1995). Erodibility. J. Hydraulic Res. 33(4), $471-494$.

Annandale, G.W. (2006). Scour technology: Mechanics and engineering practice. McGraw Hill, New York.

Armengou, J. (1991). Disipacion de energia hidraulica e pie de presa en presas boveda. $P h D$ thesis. Universitat Politechnica de Catalunya, Barcelona [in Spanish].

Asadollahi, P. (2009). Stability analysis of a single threedimensional rock block: Effect of dilatancy and high-velocity water jet impact. PhD thesis. University of Texas, Austin.

Bellin, A., Fiorotto, V. (1995). Direct dynamic force measurement on slabs in spillway stilling basins. $J$. Hydraulic Eng. 121(10), 686-693.

Beltaos, S., Rajaratnam, N. (1973). Plane turbulent impinging jets. J. Hydraulic Res. 11(1), 29-59.

Bollaert, E. (2002). Transient water pressures in joints and formation of rock scour due to high-velocity jet impact. Communication 13. Laboratory of Hydraulic Constructions, EPFL, Lausanne, Switzerland.

Bollaert, E., Schleiss, A. (2003a). Scour of rock due to the impact of plunging high velocity jets 1: A state-of-the-art review. J. Hydraulic Res. 41(5), $451-464$ 
Bollaert, E., Schleiss, A. (2003b). Scour of rock due to the impact of plunging high velocity jets 2: Experimental results of dynamic pressures at pool bottoms and in one- and twodimensional closed-end rock joints. I Hydraulic Res. 41(5), 465-480.

Bollaert, E.F.R., Schleiss, A.J. (2005). Physically based model for evaluation of rock scour due to high-velocity jet impact. $J$. Hydraulic Eng. 131(3), 153-165.

Cola, R. (1965). Energy dissipation of a high-velocity vertical jet entering a basin. Proc. $11^{\text {th }}$ IAHR congress, Leningrad 1(52), $1-13$.

Cunha, L.V., Lencastre, A.C. (1966). La dissipation de l'énergie dans un evacuateur en saut de ski. Technical Paper 288. LNEC, Lisboa [in French].

Ervine, D.A., Falvey, H.T., Withers, W. (1997). Pressure fluctuations in plunge pool floors. J. Hydraulic Res. 35(2), 257-279.

Federspiel, M.P.E.A., Bollaert, E.F.R., Schleiss, A.J. (2009). Respose of an intelligent block to symmetrical core jet impact. Proc. 33 ${ }^{\text {rd }}$ LAHR congress, Vancouver, 3573-3580.

Fiorotto, V., Rinaldo, A. (1992). Turbulent pressure fluctuations under hyraulic jumps. J. Hydraulic Res. 30(4), 499-519.

Fiorotto, V., Salandin, P. (2000). Design of anchored slabs in spillway stilling basins. J. Hydraulic Eng. 126(7), 502-512.

Franzetti, V., Tanda, M.G. (1987). Analysis of turbulent pressure fluctuation caused by a circular impinging jet. Intl. Symp. New technology in model testing in hydraulic research New Delhi, India, 85-91.

Goodman, R.E., Powell, C. (2003). Investigations of blocks in foundations and abutments of concrete dams. J. Geotech. and Geoenvir. Engng. 129(2), 105-116.

Hart, R.D., Cundall, P.A., Lemos, J. (1988). Formulation of a three-dimensional distinct element model 2: Mechanical calculations for motion and interaction of a system composed of many polyhedral blocks. Int. J. Rock Mech. Min. Sci. Geomech. Abs. 25(3), 117-125.

Hartung, F., Häusler, E. (1973). Scours, stilling basins and downstream protection under free overfall jets at dams. Proc. $11^{\text {th }}$ Int. congress on large dams Madrid Q41(R3), 39-56.

Itasca. (1999). 3DEC user's manual. Itasca, Minneapolis MN.

Jang, H.I., Lee, C.I. (2002). Development of a three-dimensional discontinuous deformation analysis technique and its application to toppling failure. Proc. $5^{\text {th }}$ Int. conf. analysis of discontinuous deformation Wuhan, China, 225-229. Balkema, Rotterdam.

Kamenev, I.A. (1965). Excavacao de um leito por um jacto em queda livre (2). Translation 474 from Trudy gidravlicheskoi laboratorii (11), 1965. LNEC, Lisbon [in Portuguese].
Liu, P.Q., Dong, J.R., Yu, C. (1998). Experimental investigation o fluctuating uplift on rock blocks at the bottom of the scour pool downstream of Three-Gorges spillway. $J$. Hydraulic Res. $36(1), 55-68$.

Lopardo, R.A. (1988). Stilling basin pressure fluctuations, Proc. Conf. Model-prototype correlation of hydraulic structures Colorado Springs, P. Burgi, ed. ASCE, New York, $56-73$

Manso, P.A. (2006). The influence of pool geometry and induced flow currents in rock scour by high-velocity plunging jets. Communiction 25. Laboratory of Hydraulic Constructions, EPFL, Lausanne, Switzerland.

Martins, R. (1973). Contribution to the knowledge on the scour action of free jets on rocky river-beds. $11^{\text {th }}$ ICOLD congress, Madrid Q41(R44), 799-814.

Mason, P.J., Arumugam, K. (1985). Free jet scour below dams and flip buckets. J. Hydraulic Eng. 111(2), 220-235.

May, R.W.P., Willoughby, I.R. (1991). Impact pressures in plunge pool basins due to vertical falling jets. Report $S R 242$. HR Wallingford, UK.

Melo, J.F., Pinheiro, A.N., Ramos, C.M. (2006). Forces on plunge pool slabs: Influence of joints location and width. $I$. Hydraulic Eng. 132(1), 49-60.

Puertas, J., Dolz, J. (1994). Criterios hidraulicos para el diseno de cuencos de disipacion de energia en presas boveda con vertido libre por coronacion. University of Catalunya, Barcelona [in Spanish].

Ramos, C.M. (1982). Energy dissipation on free jet spillways. Bases for its study in hydraulic models. Proc. trans. int. ICOLD symp. layout of dams in narrow gorges Rio de Janeiro, Brazil 1, 263-268.

Tonon, F. (2007). Analysis of single rock blocks for general failure modes under conservative and non-conservative forces. Int. J. Num. Anal. Meth. Geomech. 31(14), 1567-1608.

Tonon, F., Asadollahi, P. (2008). Validation of general single rock block stability analysis (BS3D) for wedge failure. $I n t . \%$ Rock Mech. Min. Sci. 45(4), 627-637.

Ursino, N., Salandin, P., Da Deppo, L. (2003). Fluctuating pressures at the bottom of a plunge pool. Proc. $30^{\text {th }}$ IAHR congress, Thessaloniki C, 191-198.

Yuditskii, G.A. (1967). Actual pressure on the channel bottom below ski-jump spillways. Izvestiya Vsesoyuznogo NauchnoIssledovatel-Skogo Instuta Gidrotekhiki 67, 231-240 [in Russian].

Yuditskii, G.A. (1971). Experimental prediction of rock bed scour below a ski-jump spillway dam. Trans. Vedeneev All. Union Scientific Research Institute of Hydraulic Engineering 91, 81-90. IPST, Jerusalem. 